\title{
Development of regional crop simulation modeling for jasmine under the purview of climate change: a perspective from Tamil Nadu, India
}

\begin{abstract}
It is a widely accepted fact that global warming and climate change may pose serious threats to food and livelihood securities. However, knowledge on the current impacts of climatic changes on floriculture is very limited. This paper tries to divert the attention of crop physiologists and crop simulation modelers the need and scope of research in simulation studies to understand climate change impacts on a tropical flower crops like Jasmine Jasminumsambac (Gundumalli/MaduraiMalli), Jasminumauriculatum (Mullai) and JJasminumgrandiflorum (Jathimalli/Pitchi) which is of great economic, social, religious and aesthetic value.
\end{abstract}

Keywords: regional crop simulation modeling, climate change, jasmine, floriculture, climate variability
Volume I Issue 2 - 2017

\author{
Dhanya Praveen, Andimuthu Ramachandran \\ Centre for Climate change and Adaptation Research, Anna \\ University, India
}

Correspondence: Dhanya Praveen, Centre for Climate change and Adaptation Research, Anna University, Chennai, India, Email dhanya.eptri@gmail.com

Received: July 27, 2017 | Published: November 01, 2017

\section{Introduction}

There are mounting concerns and evidences about climate change impacts on agriculture sector in general and on flowering plants in particular. There is also growing recognition that some degree of climate change impacts are now inexorable and almost all regions, sectors, and people are prone to climate change impacts to varying degrees. ${ }^{1,2}$ Over the period 1951-2012, global mean surface temperature increased approximately by $0.12^{\circ} \mathrm{C}$ per decade Although there will be advantages in some plant growth in some regions of the world, especially in higher latitudes, the overall impact of climate change on agriculture are expected to be negative, threatening global food and livelihood security. ${ }^{3}$ Real time experiments are conducted to understand the phonological disturbances in plants due to climate change. The strong negative impacts due to warming that limit plant growth, metabolism, and productivity worldwide have been reported by various researchers. As far as India is concerned, around $49 \%$ of our labor force is still depended up on agriculture and allied sector for their livelihood and climate plays a crucial role as about 55-60 per cent of the area sown is still rain-fed. Flowering plants like jasmine play an important role in the economical and livelihood space of rural and urban India, especially a state like Tamil Nadu. ${ }^{4}$ Jasmine is one of the oldest fragrant flowers cultivated in India especially in many places in Tamil Nadu. India has made noticeable advance in the production of flowers, particularly cut flowers, which have a good potential for export. Floriculture is a fast emerging and highly competitive industry in our country. Jasmine is cultivated tropical and warm temperate regions and cultivated in France, Italy, China, Japan, India, Morocco and Egypt. It has emerged as a lucrative profession with the much higher potential for returns compared to other agrihorticultural crops. Flowers are an integral part of social and cultural identity of south India. In the past, flowers were not of much economic, social, religious and aesthetic importance. Synchronization of flowering to peak market price is crucial in flower farming. Tamil Nadu is the leading producer of Jasmine in the country with an annual production of $1,20,750$ tons from a cultivated area of 15581 hectares with an average productivity of $10 \mathrm{MT} / \mathrm{Ha}$ in $201-12 .^{5}$ The major varieties cultivated in the state are Jasminumsambac (Gundumalli/ MaduraiMalli), Jasminumauriculatum (Mullai) and $J$. grandiflorum (Jathimalli/Pitchi), J. multiflorum, J. flexile, J. rigidum, J. humile, $J$. primulinum etc. The flowers harvested in the state are exported to neighboring countries like Sri Lanka, Singapore, Malaysia and the Middle East. The major Jasmine cultivating districts of Tamil Nadu are Madurai, Dindigul, Salem, Tirunelveli, Virudhunagar and Trichy. Jasmine flowers are native to India and China.

This state has a promising position as it stands second in the area under flower cultivation in entire India. Jasmine flowers are used for various purposes viz. making garlands, bouquet, decorating hair of women, religious offering etc. Jasmine is also known as the "Queen of the Night", because of its heady fragrance. It is also used for production of Jasmine concrete which is used in cosmetic and perfumery industries. More than 80 Jasmine species are found in India, of which only three species are used for commercial cultivation. ${ }^{6}$ The first two species are mainly cultivated for selling as fresh flowers whereas the last one is cultivated for concrete extraction. Jasmine flower cultivation has huge potential to create employment for women. The farmers who were into jasmine cultivation were found to be comparatively less stressed out of the external factors. As it's a perennial crop, it did not require frequent land preparations. Unlike other crops jasmine requires irrigation one in 2 weeks. In this scenario of weather aberrations and climate changes it's a pleasing fact that the Jasmines may be irrigated only at the interval of 15 days. The adverse climate during winter was a major constraint in jasmine production as flower bud development was flower opening was a serious issue. To overcome this loss, farmers opt for intercropping with short duration varieties of pulses and millets and oilseeds etc during winter (Figure 1). Higher temperature exposure beyond the threshold level eventually affects the quality and quantity of yields of desirable crops while weeds infest and pest gets proliferated. Crop simulation models are the best available methods to quantify such impacts and for evaluating the vulnerability. ${ }^{7}$ At present, there is a variety of Crop Simulation Models (CSM) available around the world such as Decision Support System for Agro-technology Transfer 
(DSSAT), ECOCROP, CROP SYST, APSIM, CERES, LINTUL, PEGASUS, INFOCROP etc. However except DSSAT (sunflower sub model), none of these models have focused on floriculture crops. Crop yield impact assessment using crop simulation model involves various processes. The critical data inputs for running the simulations are daily weather, soil parameters and crop management details. ${ }^{8,9}$
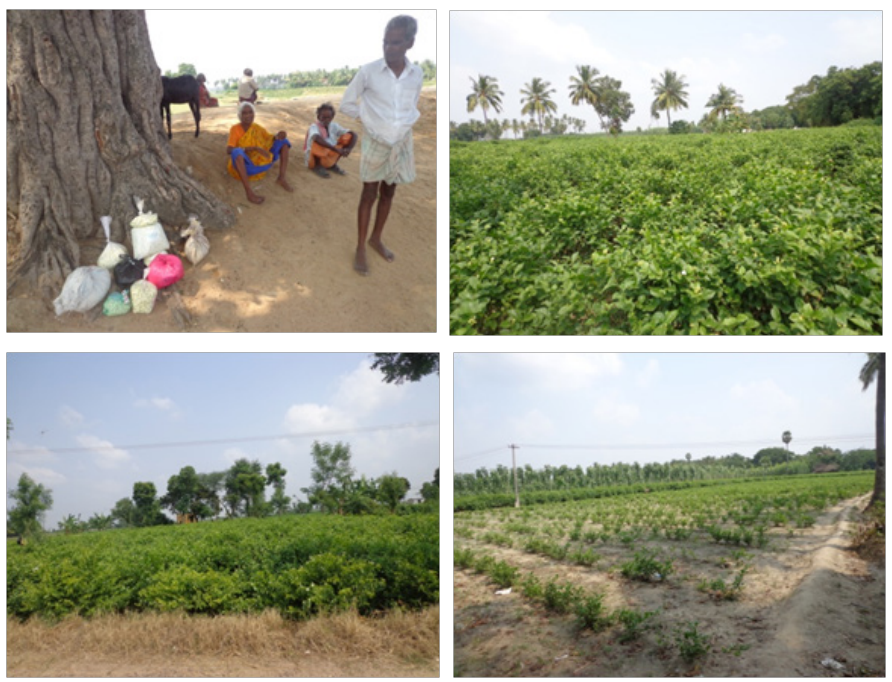

Figure I Jasmine cultivations and flower bud collections in different parts of Tamil Nadu.

There are various sub modules inside crop simulation models. The major modules are land module, management module, soil module, and weather module, and soil-plant-atmosphere module. Some models utilize mass balance principles to simulate the carbon, nitrogen, and hydrologic processes and transformations that occur within agroecosystems. ${ }^{9-12}$ Crop development proceeds through a series of growth stages based on photo thermal time or heat unit accumulation from planting to harvest. ${ }^{13-17}$ There is a wide gap and lack of regional crop simulation modeling for floriculture crops and further impact studies on its productivity focusing at local scale. It is necessary to have research studies focusing on micro and macro climatic influence on quality and quantity of flower yield .Higher temperatures may pose significant negative impacts on flower development in the purview of climatic variability and change. In tropical environment, high temperature exposure above the threshold level eventually affects the quality and the quantity of the flower buds eventually weeds infest the area and pests proliferate. Vagaries in precipitation patterns augment the likelihood of short-run crop failures and long-run production declines. Not only temperature and rainfall, but relative humidity also plays a major role in the new leaf production, the leaf expansion, the leaf area duration, the flower initiation, the flower development, the pollination, the maturity etc. Thermal stress during the most sensitive plant developmental stages may impede photosynthesis and thus its flower yield. Winter season (December to February) is a dormant season for flower crops especially Jasmine. The farmer requires polyhouses for getting sustained income and flower production.

Literature reviews shows that much of this research has addressed the consequences of warming for and distributional shifts in plants. In contrast, relatively little is known about the physiological responses of perennial plants and insect pollinators to climate warming and, in particular, how these responses might affect plant-pollinator interaction networks and flower yield directly or indirectly in a changing climatic condition. Crop simulation modelers should look into the multi thronged mutualistic interactions happens among pollinators, flowers, and climate and incorporates it in scope of the modeling processes. This approach should lead to a new urge in crop simulation research overcoming the limiting scope for simulating pollinator and flower interactions in flower crop especially on the plant responses to which include altered flower, nectar, and pollen production, could modify floral resource availability and reproductive output of pollinating insects. The production of floral scent, nectar, and pollen can also be affected by temperature.

\section{Conclusion}

Understanding the local changes with respect to climate necessitates better adaptation and future management especially for the vulnerable low lying coastal areas in the developing countries who has $50 \%$ of its workforce engaged in agriculture. It is the responsibility of the scientific community to disseminate the climate change knowledge through a Top down approach method, will help all the stakeholders including decision makers in furthering researches and policy formulations. Acquiring local level authentic information on future plausible climate change and its impacts on flower productivity will facilitate implementing site specific adaptation options in this sector.

\section{Acknowledgments}

We would like to thank all the stakeholders of Tamil Nadu for all the information/support provided.

\section{Conflict of interest}

The author declares no conflict of interest.

\section{References}

1. IPCC. Climate Change 2013: The Physical Science Basis. Contribution of Working Group I to the Fifth Assessment Report of the Intergovernmental Panel on Climate Change. In: Stocker TF, et al, editors. USA: Cambridge University Press; 2013. p. 1-1535.

2. IPCC. Climate Change 2014: Impacts, Adaptation, and Vulnerability Contribution of Working Group II to the Fifth Assessment Report of the Intergovernmental Panel on Climate Change. In: Field C, et al, editors. USA: Cambridge University Press; 2014. p. 1-1131.

3. Adger WN. Vulnerability. Global Environmental Change. 2006;16(3):268-281.

4. Avinash Tripathi. Indian Floriculture Industry-An overview, Kurukshetra. 2012. p. 37-45.

5. Kaviarasan K, Singh DR, Prawin Arya. Economic Analysis of Jasmine cultivation in Tamil Nadu. Biotech articles. 2015.

6. http://www.keralaagriculture.gov.in

7. Aggarwal PK, Banerjee B, Daryaei MG, et al. Info Crop: a dynamic simulation model for the assessment of crop yield, losses due to pest, and environmental impact of agro-ecosystem in tropical environments: II', Performance of the model'. Agricultural System. 2006;89:47-67.

8. Bhaskaran B, Ramachandran A, Jones R, et al. 'Regional climate model applications on sub-regional scales over the Indian monsoon region: The role of domain size on downscaling uncertainty'. Journal of Geophysical research. 2012;117:D10113.

9. Hoogenboom G, Jones JW, Wilkins PW, et al. 'Decision Support System for Agrotechnology Transfer': DSSAT v3. Understanding Options for Agricultural Production. 2010;7:157-177. 
10. Jones JW, Hoogenboom G, Porter CH, et al. The DSSAT cropping system model. European Journal Agronomy. 2003;18(3,4):235-265.

11. Jones PG, Thornton PK. The potential impacts of climate change in tropical agriculture: the case of maize in Africa and Latin America in 2055. Global Environmental Change. 2003;13:51-59.

12. Julián Ramírez Villegas, Charlotte Lau, Ann Kristin Köhler, et al Climate analogues: finding tomorrow's agriculture today. CGIAR Research Program on Climate Change. Agriculture and Food Security, Denmark; 2011. p. 1-12.

13. Naresh Kumar S, Aggarwal PK, Swaroopa Rani, et al. Impact of climate change on crop productivity in Western Ghats, coastal and northeastern regions of India. Current Science. 2011;101(3):1-10.
14. Boutraa T. Improvement of water use efficiency in irrigated agriculture: A Review. Journal of Agronomy. 2010;9(1):1-8.

15. Geethalakshmi V, Lakshmanan A, Rajalakshmi D, et al. Climate change impact assessment and adaptation strategies to sustain rice production in Cauvery basin of Tamil Nadu. Current Science. 2011;101(3):1-6.

16. Patel HR, Lunagaria MM, Karande BI, et al. Impact of projected climate change on groundnut in Gujarat. Journal of Agrometeorology. 2013;15(1):41-44

17. Ramaraj AP, Jagannathan R, Geethalakshmi V, et al. Climate change and rice crop duration. Journal of Agrometeorology. 2013;15(1):189-191. 